\title{
CIÊNCIANATURA
}

\section{Dinâmica de uso e cobertura da terra e análise de tendência de mudanças para o município de Caçador, SC}

Land use and land cover dynamics and trend analysis for the municipality of Caçador, SC

\begin{abstract}
Wilson Anderson Holler ${ }^{*}$, Maria Augusta Doetzer Rosot ${ }^{2}$, Marilice Cordeiro Garrastazu ${ }^{3}$, Isabella Françoso Rebutini Figueira ${ }^{4}$, Naíssa Batista da Luz ${ }^{5}$, Jéssica Caroline Maran ${ }^{6}$, Luziane Franciscon ${ }^{7}$, Yeda Maria Malheiros de Oliveira ${ }^{8}$

1,2,3,7,8 Empresa Brasileira de Pesquisas Agropecuárias, Embrapa Florestas, Colombo, PR, Brasil ${ }^{4}$ Professor permanente no Programa de Pós-Graduação em Desenvolvimento de Tecnologia do LACTEC

${ }^{5,6}$ Consultora $\mathrm{FAO} / \mathrm{ONU}$
\end{abstract}

\section{Resumo}

Esse estudo mostra a importância de tecnologias que podem ser utilizadas no planejamento territorial e monitoramento da paisagem rural. Apresenta os procedimentos metodológicos para o mapeamento, a análise e o monitoramento do uso e cobertura da terra no município de Caçador, SC, em dois momentos, 2011 e em 2014. Foi empregada classificação orientada a objetos de imagens de satélite da constelação RapidEye, conforme metodologia desenvolvida para o Inventário Florestal Nacional do Brasil. A análise de qualidade temática da classificação levou em consideração o percentual de área ocupada pelas classes: Floresta natural, Outras terras com árvores, Gramíneas e herbáceas, Floresta plantada, Solo exposto, Agricultura e pastagem, Influência urbana e Superficie com água. Os valores da acurácia global

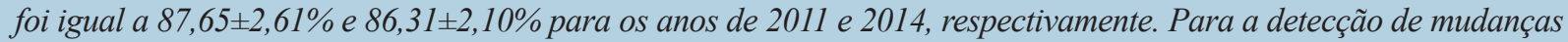
empregou-se Land Change Modeler, que se baseia em cadeias markovianas para a geração de matrizes de transição. As maiores alterações ocorreram nas classes Floresta natural (-4,6\%), Floresta plantada (2,6\%) e Agricultura e pastagem (1,9\%). Na região nordeste do município concentra-se a maior probabilidade (até 12, 04\%) de ocorrer a conversão da classe Floresta natural para classes que contemplem atividades antrópicas.

Palavras-chave: Análise espaço-temporal; Acurácia temática; Análise de tendência

\section{Abstract}

This study shows the importance of technologies that can be used in territorial planning and rural landscape monitoring. It presents the methodological procedures for the mapping, analysis and monitoring of land use and land cover in the municipality of Caçador, SC, in two moments, 2011 and 2014. An object-oriented classification of satellite images from the RapidEye constellation was used, according to the methodology developed for the National Forest Inventory of Brazil. The analysis of the thematic quality of the classification took into account the percentage of area occupied by the classes: Natural Forest, Other land with trees, Grasses and herbaceous, Planted forest, Soil exposed, Agriculture and pasture, Urban influence and Surface with water. The values of the overall accuracy were $87.65 \pm 2.61 \%$ and $86.31 \pm 2.10 \%$ for the years 2011 and 2014, respectively. Land Change Modeler, which relies on Markovian chains for the generation of transition matrices, was used to detect changes. The major changes occurred in the Natural Forest (-4.6\%), Planted Forest (2.6\%) and Agriculture and Pasture (1.9\%) classes. In the northeast region of the municipality, the highest probability (up to 12, 04\%) is the conversion of the Natural Forest class to classes that contemplate anthropic activities.

Keywords: Spatio-temporal analysis; Thematic accuracy; Trend analysis

\footnotetext{
*wilson.holler@embrapa.br
} 


\section{Introdução}

O planejamento e a execução de ações relativas à gestão do território rural dependem da disponibilidade de instrumentos de diagnóstico e análise que permitam avaliar e monitorar ecossistemas e os respectivos serviços que proveem, ambos espacialmente explícitos. Para isso é necessário, em primeiro lugar, mapear os padrões de uso e cobertura da terra.

A importância da quantificação e monitoramento das mudanças no uso e cobertura da terra é amplamente reconhecida pela comunidade científica internacional como um elemento chave no estudo de mudanças globais (SMITH et al., 2014; FOLEY et al., 2005; FEARNSIDE, 2001). Uma das tecnologias que dá suporte à estruturação de sistemas de monitoramento de mudanças nos recursos naturais em larga escala (espacial e temporal) é o imageamento por satélite (WASHINGTON-ALLEN; RAMSEY; WEST, 2004). Segundo Di Gregorio (2016), o uso e cobertura da terra podem ser determinados por meio da análise de imagens aéreas e de satélite. Os dados de sensores orbitais apresentam características fundamentais para a aplicação nos estudos de uso e cobertura da terra como a capacidade de observação e monitoramento de forma sinóptica, dinâmica e em diferentes escalas espaço-temporais que possibilitam quantificar as taxas de conversão e mudança no uso e cobertura da terra (TURNER II; LAMBIN; REENBERG, 2007). Dentre os sensores óticos, passivos, destacamse as imagens de satélite da constelação RapidEye (RE) que é composta por cinco satélites que coletam dados diariamente (visada lateral) ou semanalmente (visada vertical) de qualquer área do globo terrestre (PLANET, 2016).

Em âmbito mundial o Intergovernmental Panel on Climate Change (IPCC) (SMITH et al., 2014) evidencia o uso do sensoriamento remoto para análise do potencial de sequestro de carbono da vegetação, do solo e o mapeamento das mudanças no uso e cobertura da terra. Para o Brasil destacam-se duas políticas públicas, em âmbito federal, embasadas em informações obtidas por imagens de satélite: o Cadastro Ambiental Rural (CAR), instituído pela Lei n ${ }^{\circ}$ 12.651/2012 e regulamentado pela Instrução Normativa MMA n ${ }^{\circ}$, de 5 de maio de 2014 (BRASIL, 2012); e as operações de crédito do Programa de Garantia da Atividade Agropecuária (Proagro), de acordo com a Resolução No 4.427 do Banco Central do Brasil (BACEN, 2015).

Uma das formas de se obter mapas de uso e cobertura da terra é por meio da classificação de imagens orientada a objetos. Pixels individuais nem sempre contêm todas as informações semânticas necessárias para a interpretação das imagens, que podem estar mais bem representadas por objetos significativos da imagem e suas relações mútuas (BAATZ; SCHÄPE, 1999). Em imagens de alta resolução espacial, frequentemente pixels vizinhos podem apresentar respostas espectrais não idênticas e, ainda assim, pertencer a uma mesma classe de uso e cobertura da terra devido à heterogeneidade ou textura específicas daquela classe (BLASCHKE; STROBL, 2001). Entretanto, classificações híbridas - que possuem uma primeira etapa de classificações automáticas pixel-a-pixel empregadas, posteriormente, como input na árvore de processos da classificação orientada a objetos - têm sido usadas com sucesso no mapeamento de uso e cobertura da terra, tal como nas Unidades Amostrais de Paisagem (UAPs) do Inventário Florestal Nacional do Brasil - IFN-BR (FREITAS et al., 2016). Neste tipo de classificação, a última etapa consiste em uma verificação por interpretação visual dos polígonos/classes resultantes, o que constitui um método simples, robusto e com boa relação custo-benefício (ACHARD et al., 2017) para corrigir eventuais discrepâncias por meio de edição vetorial.

A validação de um mapa de uso e cobertura da terra inclui a avaliação da acurácia por meio da comparação entre os resultados da imagem classificada e outras fontes de informação. Para tanto, Strahler et al. 
(2006) recomendam o uso de um desenho amostral probabilístico, permitindo a estimativa da acurácia global, da acurácia do produtor e do usuário e dos erros de omissão e comissão, obtidos a partir da matriz de erro (FIGUEIREDO; VIEIRA, 2007; FOODY, 2002). Tal matriz é construída com base em pontos de referência ("verdade terrestre"), coletados em campo, na área de interesse, e no cálculo posterior dos parâmetros de acurácia. A verificação de campo, possibilita, também, coletar informações sobre o uso e cobertura das feições já mapeadas sobre as quais existam dúvidas que comprometam a qualidade do mapeamento, caracterizando um processo de reambulação (ROSOT et al.; 2017).

Segundo Bayfield (1997) apud Lang e Blaschke (2009), monitorar é registrar uma mudança. A análise de mudanças no uso e cobertura da terra é fundamental para o meio ambiente e gerenciamento de recursos naturais, planejamento do uso e cobertura da terra, conservação da biodiversidade e redução das emissões de $\mathrm{CO}_{2}$ por desmatamento e degradação florestal. Para monitora-las é necessário, em um momento inicial $\left(\mathrm{t}_{0}\right)$, obter os dados de um recorte de paisagem, com uma metodologia estabelecida. O mesmo processo (na mesma área e com a mesma metodologia) se repete em um momento posterior $\left(t_{1}\right)$. As diferenças com relação às variáveis-resposta são, então, analisadas em sua extensão, distribuição e características.

Para a detecção de mudanças de uso e cobertura da terra ao longo de um determinado período devem ser utilizados mapas referentes a duas ou mais ocasiões e calculadas as diferenças entre eles, por meio de métodos pré-definidos. Lu et al. (2004) apresentam mais de 30 métodos de detecção de mudanças divididos em sete categorias. Hussain et al. (2013) as dividem em dois grupos descrevendo 15 técnicas baseadas em pixels e 3 técnicas baseadas em análise orientada a objetos. Os métodos pertencentes à categoria classificação por pixel têm sido os mais aplicados aos estudos de detecção de mudanças (HUSSAIN et al., 2013). Dentre as desvantagens desses métodos, destacam-se a completa dependência da precisão das classificações envolvidas no estudo no resultado obtido, a necessidade de um registro de alta qualidade, além da possibilidade de as classes apresentarem uma alta variação dentro de uma mesma área, principalmente em se tratando de dados de alta resolução espacial classificados sem influência da vizinhança (LU; LI; MORAN, 2014). A detecção de mudanças baseada na classificação orientada a objetos possui algumas vantagens em relação à classificação pixel-a-pixel, pois permite a segmentação e extração de feições de imagens de alta resolução espacial e facilita a integração de processamentos de dados matriciais, como as imagens de satélite, com os dados vetoriais em um SIG (Sistema de Informações Geográficas) (BLASCHKE, 2010). Com os segmentos gerados na classificação orientada a objetos é possível obter mais informações sobre cada região segmentada tais como textura, forma e relações espaciais entre segmentos vizinhos (AGUIRRE-GUTIÉRREZ; SEIJMONSBERGEN; DUIVENVOORDEN, 2012; BOCK et al., 2005).

O planejamento e a utilização adequados dos recursos naturais exigem um estudo intensivo dos padrões de mudança de uso e cobertura da terra. Os modelos de mudança de uso e cobertura da terra geralmente detectam onde a mudança ocorrerá com base na previsão probabilística. Esses modelos podem considerar diferentes fatores de mudança, como as tendências de mudanças anteriores do uso e cobertura da terra, características topográficas, crescimento da população e distâncias para diferentes instalações (FREIER et al. 2011; GUAN et al. 2011; HALMY et al. 2015). Os dados sobre a quantidade e qualidade das mudanças são empregados na geração de modelos que, por sua vez, possibilitam analisar tendências futuras relacionadas à composição e à distribuição das classes de uso e cobertura da terra, projetadas em diferentes cenários. A análise da cadeia de Markov é a, técnica de modelagem e previsão de mudanças de uso e cobertura da terra, mais comumente 
utilizada (AGRAWAL et al., 2002).

Dessa forma, o presente trabalho teve por objetivo descrever os métodos aplicados e resultados relativos ao mapeamento do uso e cobertura da terra do município de Caçador - SC, no sul do Brasil, em dois momentos no tempo, com base em classificação híbrida de imagens RapidEye. Além disso, foram relatados os procedimentos adotados para a quantificação e qualificação das mudanças observadas nas classes de uso e cobertura, bem como estimadas as probabilidades de alteração de determinada classe entre 2011 e 2014.

\section{Materiais e métodos}

Por meio de software de processamento digital de imagens (PDI), as imagens foram corrigidas em relação ao espalhamento atmosférico e, posterirormente, normalizadas para a geração dos mosaicos do município de Caçador, SC, para os anos de 2011 e 2014. De acordo com a metodologia de classificação híbrida, as imagens foram submetidas, inicialmente, a um processo de classificação automática pixel-a-pixel nãosupervisionada. Os resultados correspondentes foram utilizados como inputs nos processos de segmentação e classificação por meio da orientação a objetos, fornecendo como resultado os mapas de uso e cobertura da terra. Todos os cálculos de áreas foram apresentados em hectares e realizados utilizando-se a Projeção Cônica Equivalente de Albers, conforme recomendado por IBGE (2014) para estudos dessa natureza. Foi adotado o Sistema de Referência Geocêntrico para as Américas (SIRGAS 2000), sistema oficial do Brasil (IBGE, 2015), com os seguintes parâmetros para o país: longitude origem: $-54^{\circ}$; latitude origem: $-12^{\circ}$; paralelo padrão $1:-2^{\circ}$; paralelo padrão $2:-22^{\circ}$.

\subsection{Descrição da área de estudo}

O município de Caçador, localizado no estado de Santa Catarina (Figura 1), foi escolhido para esse trabalho por se tratar do primeiro município brasileiro onde foi executado um inventário florestal nos moldes do IFN-BR, incluindo tanto a componente de dendrometria em campo quanto a análise de paisagem para a qual são necessários mapas de uso e cobertura da terra. Além disso, Caçador abriga a Estação Experimental da Empresa Brasileira de Pesquisa Agropecuária (Embrapa), com dados históricos de campo provenientes de projetos de pesquisa relacionadas à paisagem da região (ROSOT et al., 2013) e estudo sobre a caracterização do seu entorno usando imagem Ikonos (KURASZ et al., 2008). Tais dados foram úteis na fase de avaliação da qualidade temática e na análise temporal. O município também possui outras áreas com projetos de pesquisa como a Floresta Nacional de Caçador (Instituto Brasileiro de Desenvolvimento Florestal (IBDF), 1968) e a Estação Experimental de Caçador da Empresa de Pesquisa Agropecuária e Extensão Rural de Santa Catarina (Epagri). Adicionalmente, a área de estudo faz parte da Rede Ibero-americana de Bosques Modelo (RIABM) (FARO, 2014), para a qual as informações sobre a dinâmica de uso e cobertura serão úteis na gestão participativa do território do Bosque Modelo Caçador, que compreende toda a superfície do município.

Segundo o IBGE (2017b), o município de Caçador possui uma área de 984,285 km². Com recursos de suas próprias florestas plantadas, o município produz madeira serrada, celulose, papel, papelão, mobília, entre outros derivados. Destaca-se também a cultura do tomate, sendo o maior produtor do Sul do Brasil, além da uva, vinho, pêssego, pimentão e milho (PREFEITURA MUNICIPAL DE CAÇADOR (PMC), 2017). Essas informações indicam que a paisagem no município é marcada pelo uso e cobertura da terra de classes que se relacionam com o uso antrópico, como floresta plantada e agricultura. 
Figura 1 - Localização do município de Caçador

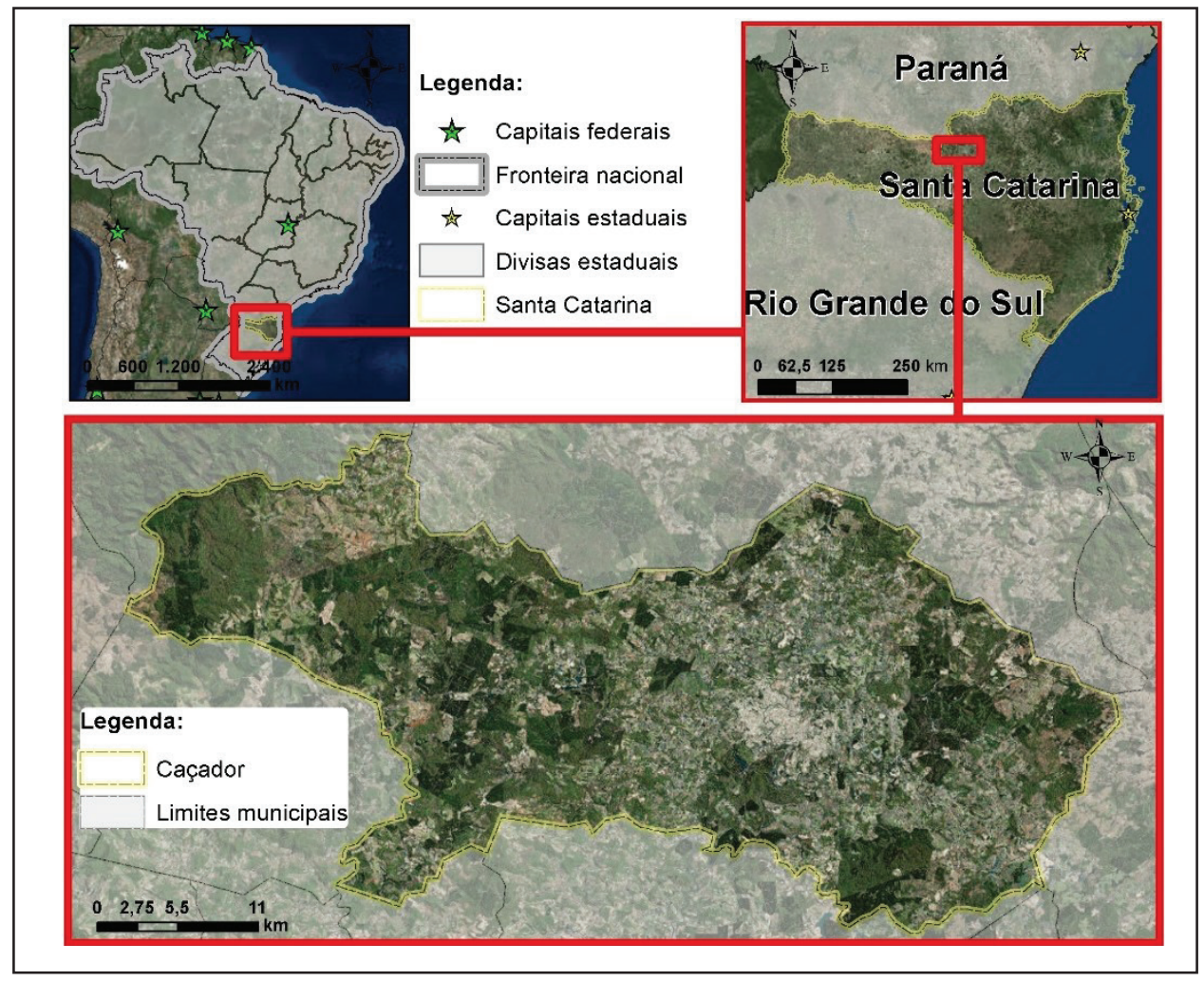

Fonte: Os autores (2018)

\subsection{Software utilizados}

Os software utilizados no desenvolvimento do trabalho foram:

- Impact Toolbox (versão 3.8) (SIMONETTI; MARELLI; EVA, 2015): conversão das imagens brutas que contém valores de radiância (níveis de cinza) para a reflectância no topo da atmosfera e a classificação pixel-a-pixel realizada de forma automática e sequencial das imagens RE para inserção posterior na árvore de processos da classificação orientada a objetos;

• ENVI (versão 5.3) (SULSOFT, 2017): análise da qualidade temática por meio dos pontos de referência e da matriz de confusão;

- eCognition (versão 9.0.1) (TRIMBLE, 2017): segmentação e a classificação orientada a objetos;

- ArcGis Desktop (versão 10.5) (ESRI, 2017): edição de dados vetoriais e matriciais. Foi utilizado para a validação temática dos mapas de uso e cobertura da terra, para validação de 985 pontos de controle e uso do LCM;

- Land Change Modeler (LCM), Modelador de Mudanças no Uso da Terra (versão 2.0) Clark Labs (2017): extensão para o software ArcGis. Empregado para mapear as mudanças na paisagem, identificar transições de classes e tendências.

A Figura 2 apresenta a síntese das etapas do processamento das imagens e análises, e em qual(is) etapa(s) cada software foi utilizado. Na etapa de classificação orientada a objetos, foram utilizados o Impact Toolbox, ArcGis e o eCognition. Na etapa da detecção de mudanças e análise de tendência do uso e cobertura 
da terra, considerando os dois anos analisados, foi utilizado o ArcGis com a extensão LCM. O ArcGis foi utilizado em todas as etapas.

Figura 2 - Síntese das etapas e software utilizados

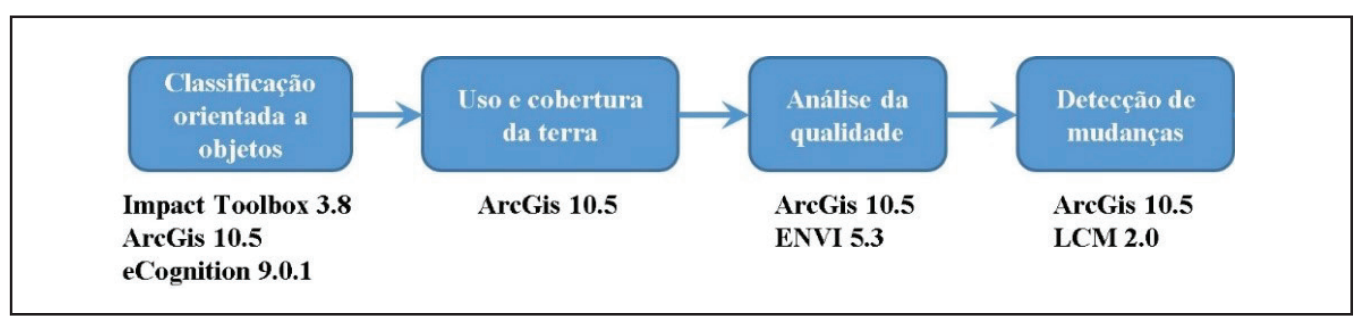

Fonte: Os autores (2018)

\subsection{Imagens da constelação RapidEye}

O Ministério do Meio Ambiente (MMA) utiliza e disponibiliza o conjunto de imagens orbitais que recobrem o país, adquiridas pela constelação RapidEye, por meio do Geocatálogo (MMA, 2017). Os satélites da constelação RapidEye (RE) são equipados com sensores idênticos que capturam imagens em cinco regiões do espectro eletromagnético (EE) com resolução espacial de 5 m (PLANET, 2016). Os sensores do RE possuem a banda Red Edge, ou vermelho de borda, desenvolvida especialmente para caracterização da vegetação, contribuindo para uma melhor discriminação de diferentes tipologias (SCHUSTER; FÖRSTER; KLEINSCHMIT, 2012; SON; CHEN, 2013). Neste trabalho foram utilizadas cinco imagens para cada ano da constelação de satélites RapidEye (RE), nível 3A, totalizando 10 imagens para as duas datas consideradas.

\subsection{Segmentação e Classificação}

O processo de classificação orientada a objetos (OBIA) iniciou-se com a segmentação das imagens RE no software eCognition utilizando uma árvore de processos (LUZ et al., 2018a), sendo a unidade mínima de mapeamento igual a $500 \mathrm{~m}^{2}$ ou 0,05 ha, padronizada de acordo com a definição de floresta adotada pela FAO.

Para a classificação dos objetos gerados com a segmentação da imagem, regras de classificação foram criadas e implementadas na forma de uma árvore de processos no software eCognition. Uma árvore de processos que incorpora a classificação pixel-a-pixel resultante do software IMPACT Toolbox e também as camadas de informação disponibilizadas por Hansen et al. (2013), Cobertura arbórea para o ano de 2014 (também referida como "remanescentes" para fins de utilização prática) e Ganho na cobertura arbórea global para o período de 2000 a 2014 (também referida como "gain” para fins de utilização prática). Foram também incorporados os seguintes índices espectrais: Ratio Vegetation Index (RVI - índice de Vegetação por Razão Simples) (JORDAN, 1969); Normalized Difference Vegetation Index (NDVI - Índice de Vegetação da Diferença Normalizada) (ROUSE et al., 1974); Soil Adjusted Vegetation Index (SAVI - Índice de Vegetação Ajustado ao Solo) (HUETE, 1988); Enhanced Vegetation Index (EVI - Índice de Vegetação Melhorado) (JUSTICE et al., 1998); Normalized Difference Water Index (NDWI - Índice de Água da Diferença Normalizada) (McFeeters, 1996) e Transformation Vegetation Index (TVI - Índice de Vegetação Transformada) (ROUSE et al., 1974) foram inseridos como parâmetros de entrada no processo de classificação orientada a objetos, para ampliar o grau de informação para caracterização dos alvos no mapeamento de uso do solo e cobertura da terra. 
Inicialmente foram segmentadas e classificadas as imagens de 2014, por possuírem qualidades radiométricas e geométricas superiores às de 2011. Os resultados da segmentação de 2014 foram, então, inseridos na árvore de processos para executar a segmentação relativa ao ano de 2011. Em locais onde ocorreu alguma alteração das classes de uso e cobertura da terra, a árvore de processos criou novos segmentos.

Figura 3 - Legenda adotada para as classes de uso e cobertura da terra

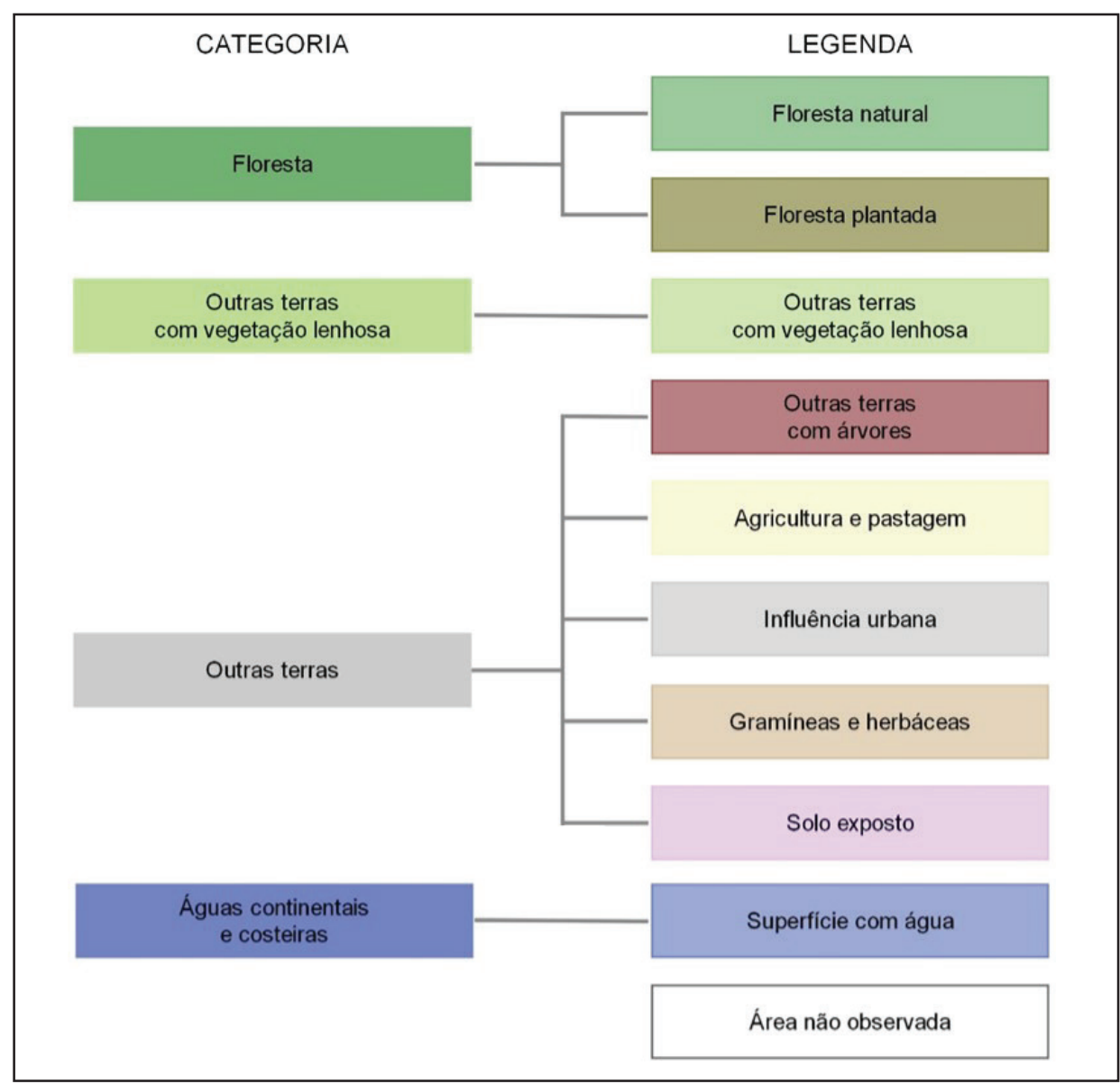

Fonte: Adaptado de Luz et al. (2018a)

A estratégia de rotulagem das classes de uso e cobertura da terra (Erro! Fonte de referência não encontrada.) seguiu a descrição fornecida no Manual de Execução do Uso e Cobertura da Terra do Inventário Florestal Nacional do Brasil (IFN-BR) (LUZ et al., 2018a, no prelo), que seguiu as diretrizes do sistema de classificação de uso e cobertura da terra da Food and Agriculture Organization of the United Nations (FAO) (2012), compatibilizado com o sistema oficial de classificação da vegetação brasileira do IBGE (IBGE, 2012). As classes temáticas adotadas podem ser agrupadas em quatro categorias: Floresta, Outras terras com vegetação lenhosa, Outras terras e Águas continentais e costeiras, apresentadas na Erro! Fonte de referência não encontrada.. A categoria Floresta contempla as classes Floresta natural e Floresta plantada. A categoria Outras terras com vegetação lenhosa contempla a classe Outras terras com vegetação lenhosa. A categoria Outras terras contempla as classes Outras terras com árvores, Agricultura e pastagem, Influência urbana, Gramíneas e herbáceas e Solo exposto. A categoria águas continentais e costeiras contempla a classe Superfície com água. Finalmente a legenda Área não observada está relacionada à ocorrência de nuvens e sombras de nuvens, assim designadas quando da impossibilidade de inferência da classe ou substituição da imagem. 
Após a execução da segmentação e classificação do mosaico de imagens por meio da árvore de processos no software eCognition, o arquivo vetorial gerado passou por uma etapa de interpretação visual e codificação das classes, de acordo com a legenda final, Figura 3. Após uma primeira edição da classificação, realizada com base em imagens de altíssima resolução espacial disponíveis no Google Earth, foram realizados levantamentos de campo, ou verificação in situ. O objetivo do trabalho de campo foi verificar a qual classe de uso e cobertura da terra pertenciam determinados polígonos gerados pela classificação digital de imagens. Os detalhes sobre os procedimentos de campo estão publicados em Rosot et al. (2017). Os dados de campo foram obtidos pelo componente 3 do projeto GEF/FAO (Fortalecimento do Marco Nacional de Conhecimento e Informação para Subsidiar Políticas de Manejo Sustentável dos Recursos Florestais) e do projeto macroprograma 3 da Embrapa Florestas (Métodos para análise, classificação e monitoramento das Paisagens Rurais Brasileiras no âmbito do Inventário Florestal Nacional do Brasil (IFN-BR)). Deve ser levado em consideração ainda o mapa de vegetação do Brasil disponibilizado pelo IBGE, resultante de atualização do projeto Radam (IBGE, 2012).

\subsection{Análise da qualidade temática}

Radoux e Bogaert (2017) recomendam a utilização das boas práticas de avaliação da acuracidade temática que envolvem a avaliação de matrizes de erro descritas por Olofsson et al. (2014) e Strahler et al. (2006). No Brasil tais práticas - adotadas no guia prático elaborado por Finegold et al. (2016), publicado pela Food and Agriculture Organization of the United Nations (FAO/ONU) - foram adaptadas ao IFN-BR (LUZ et al., 2018b). Diferenciam-se das abordagens tradicionais de avaliação de acurácia ao levar em consideração a proporção de área ocupada por cada classe no mapa gerado (Olofsson et al., 2014); os pontos de referência para a elaboração da matriz de erro, entretanto, continuam sendo baseados em uma amostragem de pontos de referência ou controle.

Para a avaliação da acuracidade temática dos mapas produzidos neste trabalho, empregou-se uma amostragem sistemática de pontos distribuídos em um grid de 1000 x 1000 m - estabelecido de acordo com as divisas municipais - perfazendo um total de 985 pontos nos 984,285 km² correspondentes à área de estudo. Tendo em vista a inexequibilidade visitas a campo em todos os pontos do grid, foi necessário optar por fontes alternativas de referência. A primeira delas consistiu no próprio mosaico das imagens RapidEye (RE), utilizado para a elaboração do mapa de de uso e cobertura. Cada ponto do grid foi classificado de acordo com a legenda pré-definida (Erro! Fonte de referência não encontrada.) por meio de interpretação visual em tela, observando-se o centro do pixel correspondente.

Adicionalmente foram empregados dados de maior resolução espacial e temporal como fonte de referência complementar às imagens RE, tais como as imagens do Google Earth, ainda de acordo com as boas práticas citadas por Olofsson et al. (2014). Também foram utilizadas imagens e vídeos obtidos por Drones, para verificação em campo (ROSOT et al., 2017). O conjunto dos pontos de controle foi empregado para avaliação e validação do mapa de uso e cobertura, representando a verdade de campo a ser utilizada no cálculo da matriz de confusão e demais coeficientes de concordância.

Os valores da matriz de confusão (FOODY, 2002) - também denominada matriz de erros -foram ponderados pelos pesos de cada classe (OLOFSSON et al., 2014; LUZ et al., 2018b). Adicionalmente aos parâmetros de acurácia geral, também foram calculadas as acurácias do usuário e do produtor para cada classe mapeada. 


\subsection{Deteç̧ão de Mudanças}

Para a detecção de mudanças e análise de superfície de tendência de alteração do uso e cobertura da terra foi utilizada a extensão LCM, para o ArcGis. O LCM usa como dados de entrada do modelo, dois mapas de uso e cobertura da terra, que, no presente trabalho, correspondem aos anos de 2011 e 2014 . A partir desses mapas o programa calcula a quantidade de mudanças, com base em cadeias markovianas, resultando em matrizes de transição.

A análise da cadeia de Markov é uma abordagem de modelagem estocástica que prevê um certo estado de um sistema de grande escala em um determinado momento com base no estado em um momento anterior. É uma técnica importante para projetar e explorar cenários futuros que ajudem a entender e a descrever quantitativamente processos espacialmente explícitos (VELDKAMP; LAMBIN, 2001). Segundo Rahman et al. (2017), a análise de tendência de mudança oferece a oportunidade de avaliar e orientar a política atual e futura do uso da terra. Nas cadeias markovianas, o modelo de simulação considera que os estados ou condições anteriores são irrelevantes para a predição dos estados seguintes, desde que o estado inicial seja conhecido (MARKOV, 1971). Segundo Ruhoff, Fantin-Cruz e Collischonn (2010), esse método assume que toda informação do passado está concentrada no presente estado do sistema. A análise de superfície de tendência, baseada nas cadeias markovianas, é um procedimento de interpolação que desagrega os padrões gerais, obtendose uma variação de maior refinamento nos dados. Esse tipo de análise foi projetada para extrair uma componente regional de um mapa, como a localização de uma tendência de mudança de uso e cobertura da terra de classes específicas (VÁCLAVÍK; ROGAN, 2009). As projeções de Markov baseiam-se no pressuposto de que as taxas de mudança observadas durante o período de calibração permanecerão as mesmas durante o período de simulação Rahman et al. (2017).

A partir dos dados de uso e cobertura da terra, gerados a partir de imagens orbitais de 2011 e 2014, o LCM calculou as superfícies correspondentes às áreas onde houve mudança de classe, identificando quais as transições ocorridas, tanto em termos absolutos como percentuais. Em uma segunda etapa o programa calculou as probabilidades de alterações de uso do solo (análise de tendência de mudança de determinada classe para outra), para ajuste de um modelo de simulação baseado em cadeias markovianas.

\section{Resultados e discussão}

\subsection{Classificação do Uso e Cobertura da Terra para os anos de 2011 e 2014}

Os resultados da classificação de imagens multitemporais permitiram a análise da dinâmica da paisagem entre 2011 e 2014. Tais resultados (Figura 4 e Tabela 2) mostraram a maior importância relativa em termos percentuais de área de três classes de uso e cobertura da terra: Floresta natural (2011 com 47\% e 2014 com 42\%), seguida pelas classes Floresta plantada (2011 com 28\% e 2014 com 30\%), Agricultura e pastagem (2011 com 21\% e 2014 com 23\%) e, com um percentual menor, a classe Influência urbana (2011 e 2014 com 3\%). Quase sem representatividade percentual, encontram-se as classes: Gramíneas e herbáceas (2011 e 2014 com 1\%), Superfície com água (2011 e 2014 com 1\%), Outras terras com árvores (2011 com 0\% e 2014 com 1\%) e Solo exposto (2011 e 2014 com 0\%). As classes Floresta plantada e Agricultura e pastagem são muito representativas em função de o município ter uma economia fortemente baseada na silvicultura e agricultura. 
Figura 4 - Classificação do Uso e Cobertura da Terra de 2011 e 2014

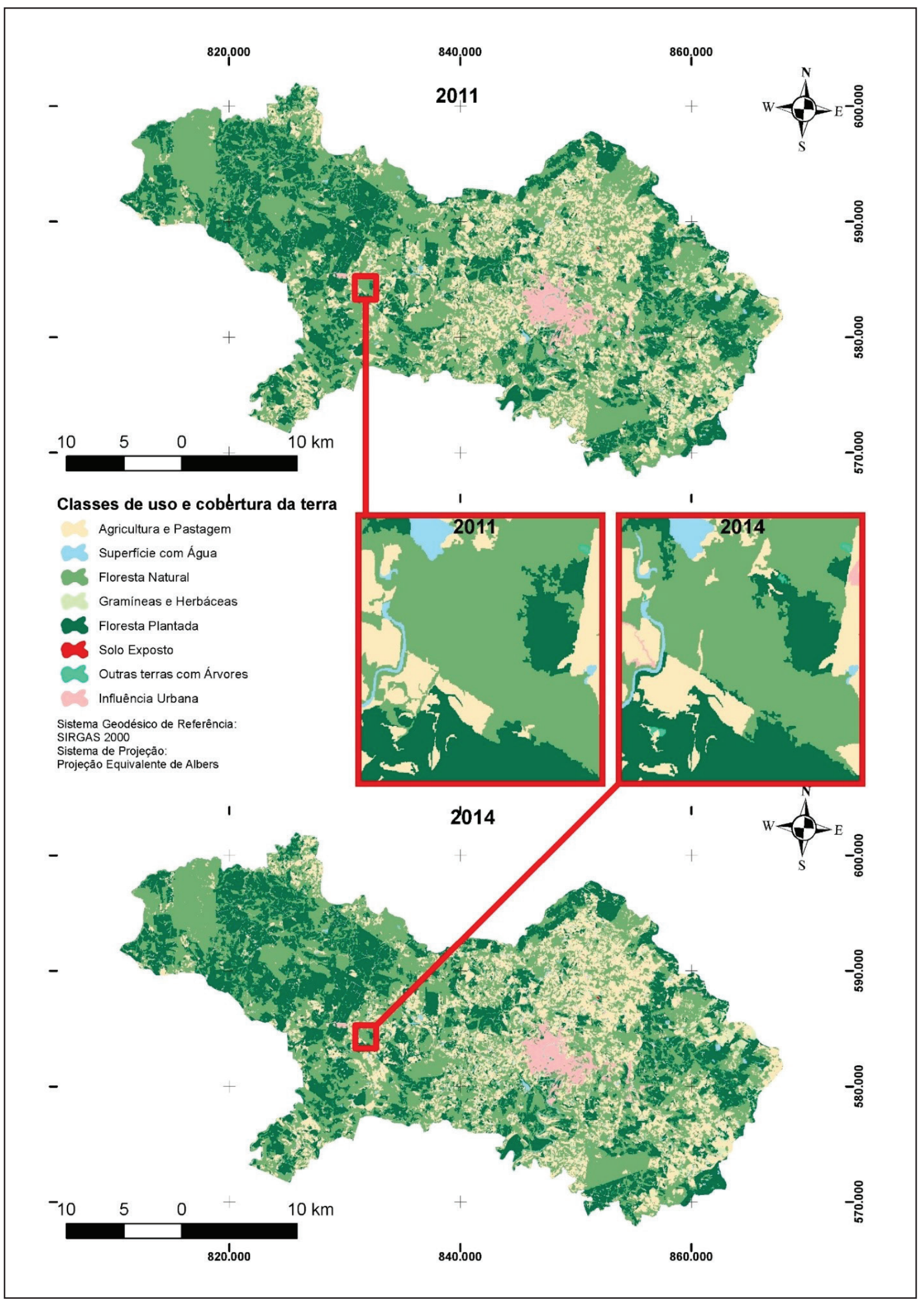

Fonte: Os autores (2018) 
Tabela 1 - Classes de uso e cobertura da terra em Caçador

\begin{tabular}{l|c|c|c|c|c|c}
\hline \multirow{2}{*}{ Classe } & \multicolumn{2}{|c|}{2011} & \multicolumn{2}{c|}{2014} & \multicolumn{2}{c}{2014 - 2011 } \\
\cline { 2 - 7 } & Área (ha) & \% & Área (ha) & \% & Área (ha) & $\%$ \\
\hline Floresta natural & 45857 & $47 \%$ & 41340 & $42 \%$ & -4517 & $-5 \%$ \\
\hline Outras terras com árvores & 484 & $0 \%$ & 647 & $1 \%$ & 163 & $1 \%$ \\
\hline Gramíneas e herbáceas & 700 & $1 \%$ & 633 & $1 \%$ & -67 & $0 \%$ \\
\hline Floresta plantada & 27124 & $28 \%$ & 29691 & $30 \%$ & 2567 & $2 \%$ \\
\hline Solo exposto & 3 & $0 \%$ & 3 & $0 \%$ & 0 & $0 \%$ \\
\hline Agricultura e pastagem & 20339 & $21 \%$ & 22179 & $23 \%$ & 1840 & $2 \%$ \\
\hline Influência urbana & 2801 & $3 \%$ & 2766 & $3 \%$ & -35 & $0 \%$ \\
\hline Superfície com água & 1118 & $1 \%$ & 1169 & $1 \%$ & 51 & $0 \%$ \\
\hline
\end{tabular}

Fonte: Os autores (2018)

\subsection{Avaliação da Acurácia Temática}

A análise de qualidade da classificação de uso e cobertura da terra para os anos de 2011 e 2014 consistiu na verificação dos 985 pontos de controle distribuídos sistematicamente sobre o município de Caçador e na avaliação dos parâmetros de acuracidade calculados por meio da matriz de erros. A análise da qualidade temática é fundamental para verificar a confiabilidade dos mapas de uso e cobertura da terra.

Na Tabela 2 estão apresentados os números absolutos e percentuais de pontos de controle para cada classe, considerando os 985 pontos de controle empregados. Dentre esses, a maioria está na classe Floresta natural seguida das classes Floresta plantada e Agricultura e pastagem em 2011. Em 2014 a maioria está na classe Floresta natural seguida das classes Agricultura e pastagem e Floresta plantada. A classe Outras terras com vegetação lenhosa não foi encontrada na classificação, já que caracteriza um tipo de formação natural de porte arbustivo que não ocorre na região. A classe Solo exposto possui área muito pequena e, apesar de existir no resultado da classificação, não foi detectada em nenhum dos 985 pontos de controle.

Tabela 2 - Número de pontos de controle absoluto e percentual para cada classe de uso e cobertura da terra

\begin{tabular}{|c|c|c|c|c|}
\hline \multirow{2}{*}{ CLASSE } & \multicolumn{2}{|c|}{2011} & \multicolumn{2}{|c|}{2014} \\
\hline & " $\mathrm{N}^{\circ}$ PONTOS & \% PONTOS & " No PONTOS $^{\circ}$ & \% PONTOS \\
\hline Área não observada (ANO) & - & 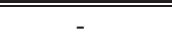 & 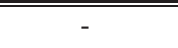 & 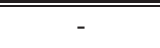 \\
\hline Floresta natural (FN) & 444 & 45,08 & 428 & 43,45 \\
\hline Outras terras co & & & & \\
\hline m vegetação lenhosa (OTVL) & - & - & - & - \\
\hline Outras terras com árvores (OTA) & 3 & 0,30 & 5 & 0,51 \\
\hline Gramíneas e herbáceas (GH) & 5 & 0,51 & 6 & 0,61 \\
\hline Floresta plantada (FP) & 257 & 26,09 & 251 & 25,48 \\
\hline Solo exposto (SE) & - & - & - & - \\
\hline Agricultura e pastagem (AP) & 241 & 24,47 & 256 & 25,99 \\
\hline Influência urbana (IU) & 31 & 3,15 & 35 & 3,55 \\
\hline Superfície com água (SA) & 4 & 0,41 & 4 & 0,41 \\
\hline Total & 985 & 100 & 985 & 100 \\
\hline
\end{tabular}

Fonte: Os autores (2018) 
Na Tabela 3 estão apresentados o número de segmentos (polígonos) e sua respectiva área em cada uma das nove classes de uso e cobertura da terra. Também é apresentado o peso (Wi) de cada classe na análise de acurácia. A classe Floresta natural é predominante no município de Caçador em 2011. A classe Floresta natural representa $40 \%$ e a classe Floresta Plantada, 30\% no município em 2014.

Tabela 3 - Dados dos segmentos e área de cada classe de uso e cobertura da terra

\begin{tabular}{l|cccc|cccc}
\hline CLASSE & FREQ. & AREA (ha) & AREA (\%) & $\mathbf{w}_{\mathbf{i}}$ & FREQ. & AREA (ha) & AREA (\%) & $\mathbf{w}_{\mathbf{i}}$ \\
& $\mathbf{2 0 1 1}$ & $\mathbf{2 0 1 1}$ & $\mathbf{2 0 1 1}$ & $\mathbf{2 0 1 1}$ & $\mathbf{2 0 1 4}$ & $\mathbf{2 0 1 4}$ & $\mathbf{2 0 1 4}$ & $\mathbf{2 0 1 4}$ \\
\hline \hline ANO & - & - & - & - & - & - & - & - \\
FN & 1558 & 45820,46 & 46,59 & 0,4659 & 1808 & 41306,60 & 42,00 & 0,4200 \\
OTVL & - & - & - & - & - & - & - & - \\
OTA & 2340 & 487,53 & 0,50 & 0,0050 & 3016 & 650,19 & 0,66 & 0,0066 \\
GH & 153 & 699,33 & 0,71 & 0,0071 & 139 & 632,18 & 0,64 & 0,0064 \\
FP & 953 & 27102,15 & 27,56 & 0,2756 & 1318 & 29666,90 & 30,16 & 0,3016 \\
SE & 1 & 3,15 & 0,00 & 0,0000 & 1 & 3,15 & 0,00 & 0,0000 \\
AP & 4021 & 20321,13 & 20,66 & 0,2066 & 4437 & 22159,66 & 22,53 & 0,2253 \\
IU & 1582 & 2798,43 & 2,85 & 0,0285 & 1788 & 2763,40 & 2,81 & 0,0281 \\
SA & 2032 & 1117,31 & 1,14 & 0,0114 & 2369 & 1167,73 & 1,19 & 0,0119 \\
\hline Total & $\mathbf{1 2 6 4 0}$ & $\mathbf{9 8 3 4 9 , 5 1}$ & $\mathbf{1 0 0}$ & $\mathbf{1}$ & $\mathbf{1 4 8 7 6}$ & $\mathbf{9 8 3 4 9 , 8 2}$ & $\mathbf{1 0 0}$ & $\mathbf{1}$
\end{tabular}

Fonte: Os autores (2018).

Legenda: FN = Floresta Natural, OTVL = Outras Terras com Vegetação Lenhosa, OTA = Outras terras com árvores, GH = Gramíneas e Herbáceas, $\mathrm{FP}=$ Floresta Plantada, $\mathrm{SE}=$ Solo Exposto, AP = Agricultura e Pastagem, IU = Influência Urbana, SA = Superfície com Água; $\mathrm{ANO}=$ Área não observada; $\mathrm{w}_{\mathrm{i}}=$ proporção de cada classe de uso e cobertura em relação à área total mapeada.

Na Tabela 4 está apresentada a matriz de erro ponderada pela proporção de área, e não a contagem de pixels, estimada para cada classe de uso e cobertura da terra para 2011. As classes Outras terras com árvores, Gramíneas e herbáceas e Superfície com água apresentam valores menores devido ao fato de a proporção das áreas ser menor e sua ocorrência ser dispersa na paisagem. A diagonal principal da matriz representa o peso que cada classe tem na avaliação da acuracidade temática, enquanto os elementos fora da diagonal contemplam os pesos de cada erro de associação entre as classes, ou seja, o peso da divergência entre as classes.

A Tabela 5 apresenta a matriz de erro ponderada pela proporção de área estimada para cada classe de uso e cobertura da terra para 2014. A classe Outras terras com árvores apresenta o menor valor devido ao fato de a proporção de áreas ser muito pequena e a ocorrência ser muito dispersa. 
Tabela 4 - Matriz de erro ponderada pela área para 2011

\begin{tabular}{|c|c|c|c|c|c|c|c|c|c|c|c|c|c|}
\hline & \multirow[b]{2}{*}{ Classe } & \multicolumn{10}{|c|}{$\mathbf{p}_{\mathrm{ij}}$} & \multirow{2}{*}{$\begin{array}{c}\mathrm{p}_{\mathrm{i} .} \\
\text { Total }\end{array}$} & \multirow{2}{*}{$\begin{array}{c}\mathbf{U}_{\mathrm{i}} \\
\text { Usuário }\end{array}$} \\
\hline & & ANO & FN & OTVL & OTA & $\mathrm{GH}$ & FP & $\mathrm{SE}$ & $\mathrm{AP}$ & IU & SA & & \\
\hline \multirow{10}{*}{$\equiv$} & ANO & - & - & - & - & - & - & - & - & - & - & - & - \\
\hline & $\mathrm{FN}$ & - & 0,4201 & - & 0,0011 & 0,0000 & 0,0203 & - & 0,0235 & 0,0011 & 0,0000 & 0,4659 & 0,9016 \\
\hline & OTVL & - & - & - & - & - & - & - & - & - & - & - & - \\
\hline & OTA & - & 0,0000 & - & 0,0033 & 0,0000 & 0,0017 & - & 0,0000 & 0,0000 & 0,0000 & 0,0050 & 0,6667 \\
\hline & $\mathrm{GH}$ & - & 0,0000 & - & 0,0000 & 0,0047 & 0,0000 & - & 0,0024 & 0,0000 & 0,0000 & 0,0071 & 0,6667 \\
\hline & FP & - & 0,0361 & - & 0,0000 & 0,0000 & 0,2325 & - & 0,0070 & 0,0000 & 0,0000 & 0,2756 & 0,8436 \\
\hline & SE & - & - & - & - & - & - & - & - & - & - & - & - \\
\hline & $\mathrm{AP}$ & - & 0,0119 & - & 0,0000 & 0,0009 & 0,0046 & - & 0,1864 & 0,0028 & 0,0000 & 0,2066 & 0,9022 \\
\hline & IU & - & 0,0009 & - & 0,0000 & 0,0000 & 0,0000 & - & 0,0037 & 0,0239 & 0,0000 & 0,0285 & $\mathbf{0 , 8 3 8 7}$ \\
\hline & SA & - & 0,0000 & - & 0,0000 & 0,0000 & 0,0000 & - & 0,0043 & 0,0014 & 0,0057 & 0,0114 & 0,5000 \\
\hline $\mathbf{p}_{. j}$ & Total & - & 0,4690 & - & 0,0044 & 0,0057 & 0,2590 & - & 0,2272 & 0,0291 & 0,0057 & & \\
\hline $\mathbf{P}_{\mathbf{j}}$ & Produtor & - & 0,8967 & - & 0,7561 & $\mathbf{0 , 8 3 7 7}$ & $\mathbf{0 , 8 9 7 7}$ & - & 0,8205 & 0,8199 & 1,0000 & & \\
\hline
\end{tabular}

Fonte: Os autores (2018).

Legenda: FN = Floresta Natural, OTVL = Outras Terras com Vegetação Lenhosa, OTA = Outras terras com árvores, GH = Gramíneas e Herbáceas, $\mathrm{FP}=$ Floresta Plantada, $\mathrm{SE}=$ Solo Exposto, $\mathrm{AP}=$ Agricultura e Pastagem, $\mathrm{IU}=$ Influência Urbana, $\mathrm{SA}=$ Superfície com Água e $\mathrm{ANO}=$ Área não observada. $\mathrm{Ui}=$ percentual de acerto de acordo com a acuracidade do usuário e $\mathrm{Pj}=$ percentual de acerto de acordo com a acuracidade do produtor.

Tabela 5 - Matriz de erro ponderada pela área para 2014

\begin{tabular}{|c|c|c|c|c|c|c|c|c|c|c|c|c|c|}
\hline & \multirow[b]{2}{*}{ Classe } & \multicolumn{10}{|c|}{$\mathbf{p}_{\mathrm{ij}}$} & \multirow{2}{*}{$\begin{array}{c}\mathrm{p}_{\mathrm{i} .} \\
\text { Total }\end{array}$} & \multirow{2}{*}{\begin{tabular}{|c|}
$\mathrm{U}_{\mathbf{i}}$ \\
Usuário
\end{tabular}} \\
\hline & & ANO & FN & OTVL & OTA & $\mathrm{GH}$ & $\mathrm{FP}$ & $\mathrm{SE}$ & AP & $\mathrm{IU}$ & SA & & \\
\hline \multirow{10}{*}{$=$} & ANO & - & - & - & - & - & - & - & - & - & - & - & - \\
\hline & FN & - & 0,3878 & - & 0,0011 & 0,0000 & 0,0086 & - & 0,0150 & 0,0064 & 0,0011 & 0,4200 & 0,9233 \\
\hline & OTVL & - & - & - & - & - & - & - & - & - & - & - & - \\
\hline & OTA & - & 0,0033 & - & 0,0008 & 0,0000 & 0,0008 & - & 0,0017 & 0,0000 & 0,0000 & 0,0066 & 0,1250 \\
\hline & $\mathrm{GH}$ & - & 0,0011 & - & 0,0011 & 0,0043 & 0,0000 & - & 0,0000 & 0,0000 & 0,0000 & 0,0064 & 0,6667 \\
\hline & $\mathrm{FP}$ & - & 0,0545 & - & 0,0000 & 0,0010 & 0,2316 & - & 0,0136 & 0,0010 & 0,0000 & 0,3016 & 0,7677 \\
\hline & SE & - & - & - & - & - & - & - & - & - & - & - & - \\
\hline & $\mathrm{AP}$ & - & 0,0049 & - & 0,0000 & 0,0010 & 0,0039 & - & 0,2107 & 0,0049 & 0,0000 & 0,2253 & 0,9353 \\
\hline & IU & - & 0,0008 & - & 0,0017 & 0,0000 & 0,0000 & - & 0,0066 & 0,0190 & 0,0000 & 0,0281 & 0,6765 \\
\hline & SA & - & 0,0000 & - & 0,0000 & 0,0000 & 0,0000 & - & 0,0030 & 0,0000 & 0,0089 & 0,0119 & $\mathbf{0 , 7 5 0 0}$ \\
\hline $\mathbf{p}_{. \mathrm{j}}$ & Total & - & 0,4523 & - & 0,0046 & 0,0062 & 0,2449 & - & 0,2506 & 0,0313 & 0,0100 & & \\
\hline $\mathbf{P}_{\mathrm{j}}$ & Produtor & - & $\mathbf{0 , 8 5 7 3}$ & - & $\mathbf{0 , 1 7 8 7}$ & 0,6879 & 0,9457 & - & 0,8408 & 0,6076 & 0,8924 & & \\
\hline
\end{tabular}

Fonte: Os autores (2018)

Legenda: FN = Floresta Natural, OTVL = Outras Terras com Vegetação Lenhosa, OTA = Outras terras com árvores, GH = Gramíneas e Herbáceas, FP = Floresta Plantada, $\mathrm{SE}=$ Solo Exposto, AP = Agricultura e Pastagem, IU = Influência Urbana, SA = Superfície com Água e $\mathrm{ANO}=$ Área não observada. $\mathrm{Ui}=$ percentual de acerto de acordo com a acuracidade do usuário e $\mathrm{Pj}=$ percentual de acerto de acordo com a acuracidade do produtor. 
Para 2011 a estimativa de acurácia global (A), ponderada pela proporção de área de cada classe, foi igual a 0,8765. Também foi estimada a variância da acurácia global ( $\mathrm{V}^{\top}(\mathrm{A})$ ), igual a 0,000110777. A partir da Variância foi calculado o Intervalo de Confiança (I.C.) de 95\% de probabilidade para a Acurácia Global ponderada pela proporção de área de cada classe, igual a 87,65 $\pm 2,61 \%$.

Para 2014 a estimativa de acurácia global (A), ponderada pela proporção de área de cada classe, foi igual a 0,8631. Também foi estimada a variância da acurácia global ( $\mathrm{V}^{\top}(\mathrm{A})$ ), igual a 0,000114405. A partir da Variância foi calculado o Intervalo de Confiança (I.C.) de 95\% de probabilidade para a Acurácia Global ponderada pela proporção de área de cada classe, igual a $86,31 \pm 2,10 \%$.

De acordo com Lillesand, Kiefer e Chipman (2015), valores de acurácia global acima de $80 \%$ são considerados excelentes. Neste trabalho foi adotado o mesmo critério dos autores, para incorporação das áreas das classes na análise de qualidade temática. Estes resultados atestam a qualidade temática do resultado obtido na classificação do uso e cobertura da terra para 2011 e 2014, permitindo sua utilização na avaliação da dinâmica das classes de uso e cobertura da terra.

\subsection{Detecção de Mudanças Analisando as Classes de Uso e Cobertura da Terra em 2011 e 2014}

Após a avaliação da qualidade temática, foram executados os procedimentos para a detecção das mudanças ocorridas entre 2011 e 2014 no município de Caçador, com base nos mapas de uso e cobertura da terra correspondentes. Nessa avaliação foi utilizada a extensão LCM do ArcGis para identificar a localização e magnitude das maiores mudanças entre categorias de uso e cobertura da terra, permitindo gerar gráficos de perdas e ganhos de área entre as classes.

Em relação à dinâmica de uso e cobertura da terra no período, os resultados obtidos (Figura 5) mostraram a diminuição da área da classe Floresta natural (-4,6\%), representada pela barra horizontal no tom verde claro, e um aumento das classes Floresta plantada (2,6\%), representada pela barra horizontal no tom verde escuro, e Agricultura e pastagem (1,9\%), representada pela barra horizontal no tom bege claro; as alterações de outras classes não chegam a 1\%. Esses resultados são apresentados na forma de gráficos, contendo valores porcentuais das alterações das áreas ocupadas por cada classe, como demonstrado na Figura 5.

Avaliou-se também quais foram as classes que mais tiveram influência sobre a alteração de determinada classe. Quando se considera a classe Floresta natural como classe principal, é possível constatar que as classes Agricultura e pastagem (barra horizontal em tom bege claro), e Floresta plantada (barra horizontal em verde escuro), são as que mais tiveram contribuição na sua alteração em área ocupada no município, sendo -1,3\% e $0,9 \%$ respectivamente, conforme mostrado na Figura 6 . As alterações entre a classe Floresta natural e as outras duas classes era esperada devido à importância econômica que a agricultura e a silvicultura têm para o município de Caçador (PMC, 2017). 
Figura 5 - Alterações porcentuais das áreas das classes de uso e cobertura entre 2011 e 2014

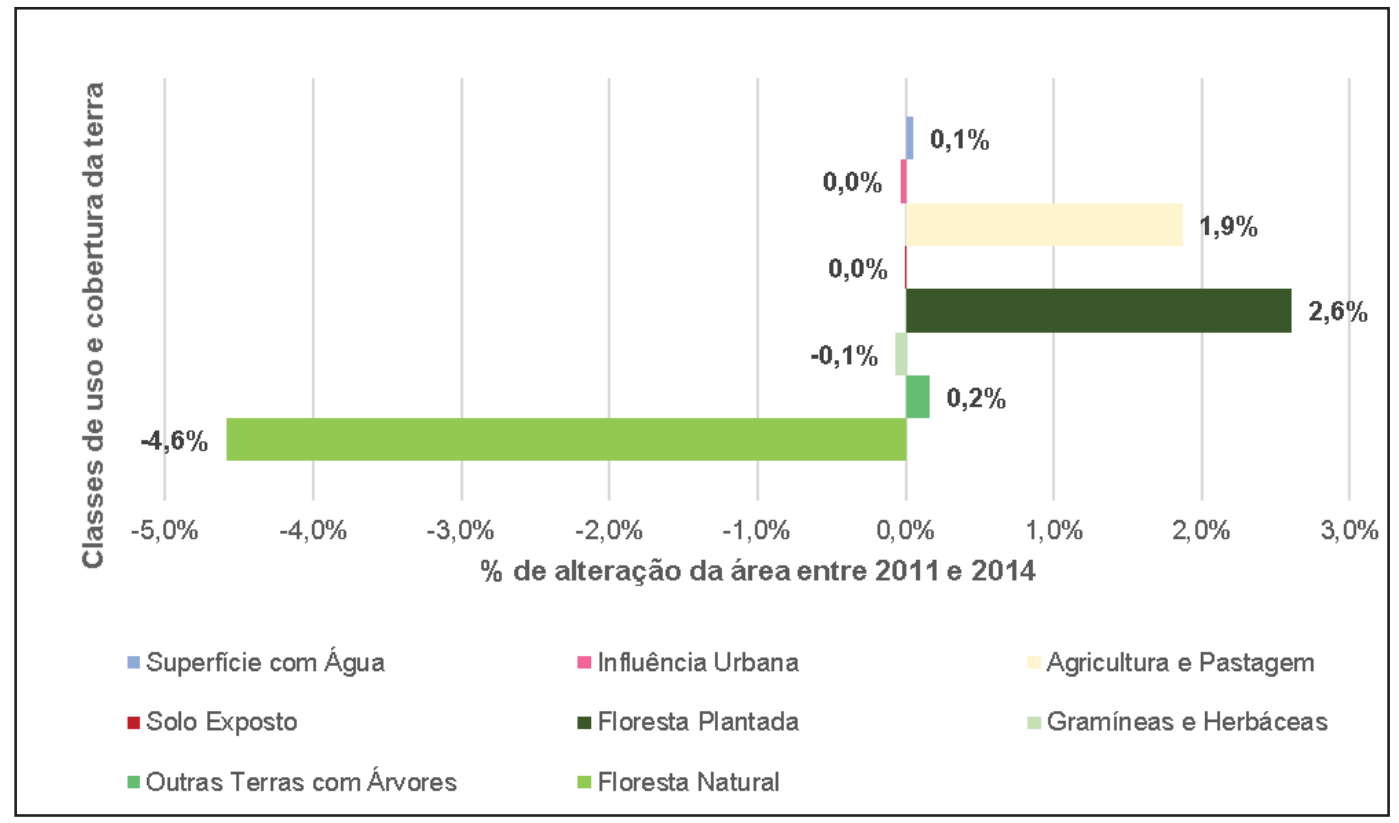

Fonte: Os autores (2018)

Figura 6 - Classes que mais contribuíram para a alteração da classe Floresta natural

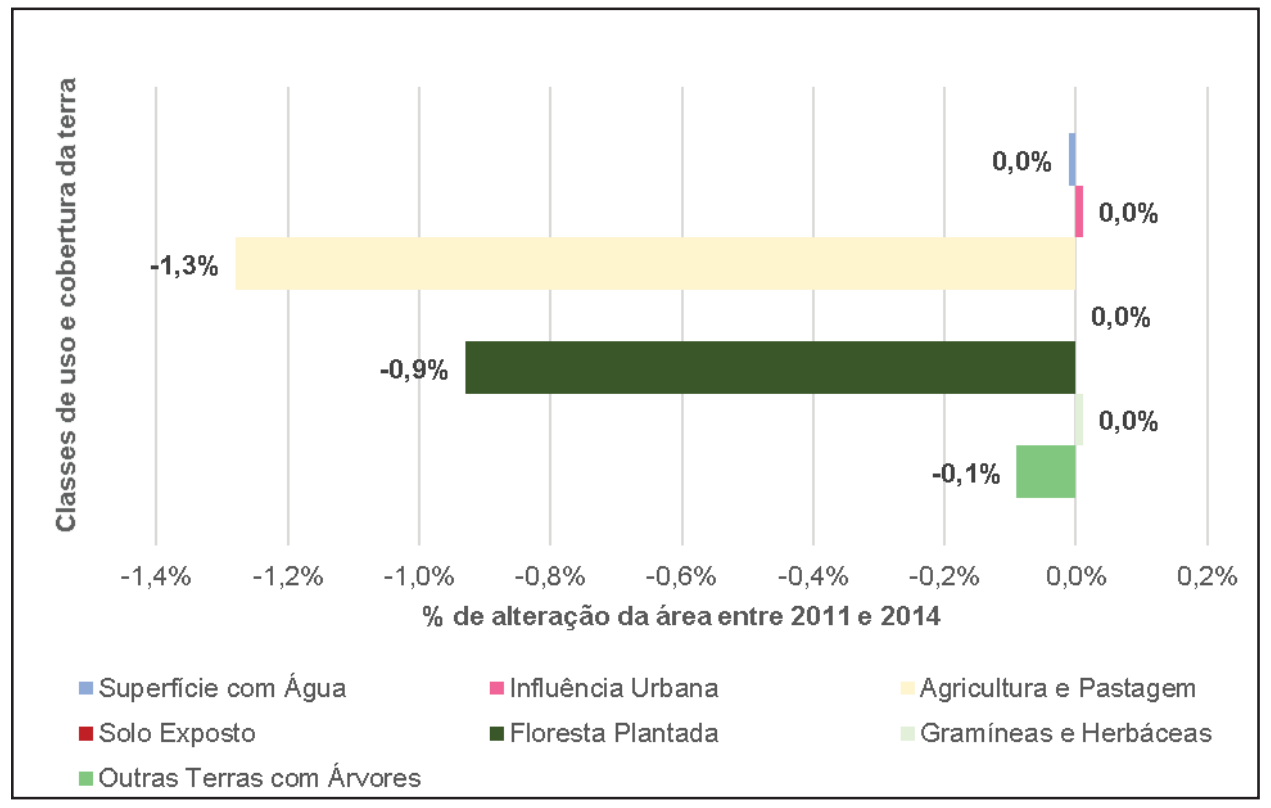

Fonte: Os autores (2018)

Além da quantificação e análise de quais classes mais influenciam a alteração de outra, os dados foram espacializados (Figura 7) mostrando onde se localizam as mudanças das classes. Na Figura 7 estão apresentadas 
as localizações das perdas e ganhos da classe Floresta natural. Polígonos em cor vermelha representam locais de perda de área da classe Floresta natural e, os em cor verde, onde houve ganho de área.

Figura 7 - Localização das alterações das classes de uso e cobertura da terra entre 2011 e 2014

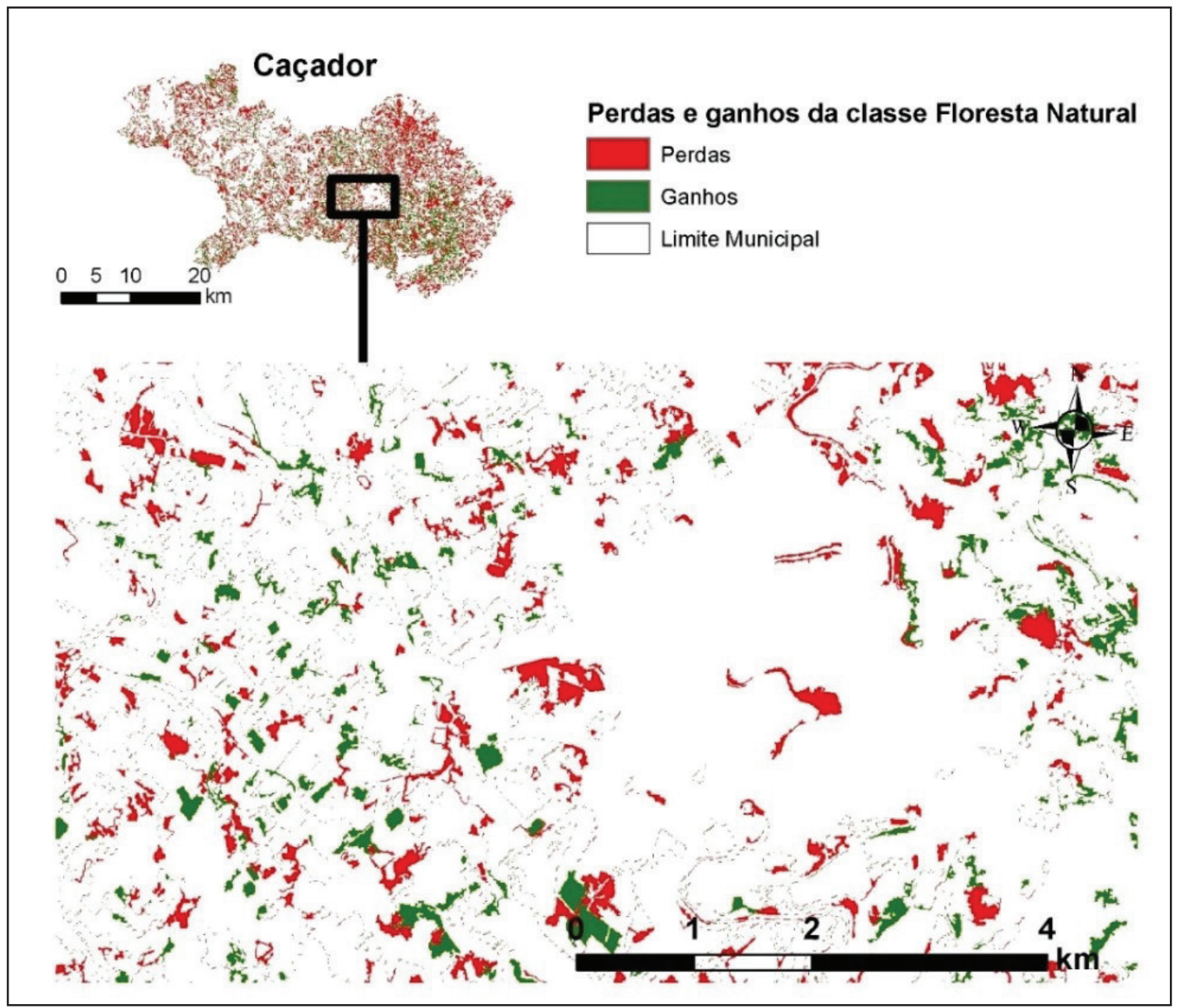

Fonte: Os autores (2018)

A partir dos mapas de uso e cobertura da terra para 2011 e 2014, o LCM permitiu analisar as probabilidades de alteração das classes, indicando os locais com maiores chances de sofrer modificações no futuro (Figura 8). Essa análise foi realizada utilizando a extensão LCM e o programa ArcGis. O LCM calculou a quantidade e a probabilidade de mudanças, com base em cadeias markovianas, para os próximos três anos, ou seja, para o ano de 2017.

Na Figura 8 está representada a probabilidade de alteração da classe Floresta natural para a classe Agricultura e pastagem, considerando um período de três anos (2014-2017). Os valores indicam onde existe a maior probabilidade de haver alteração da classe Floresta natural, se ela ocorrer no local. Os locais em cor vermelha têm maior probabilidade $(12,04 \%)$ de ser convertidos para uso antrópico. Os locais em cor verde indicam onde há menor chance de ocorrer essa alteração. 
Figura 8 - Probabilidade de mudança da classe Floresta natural para a Agricultura e pastagem

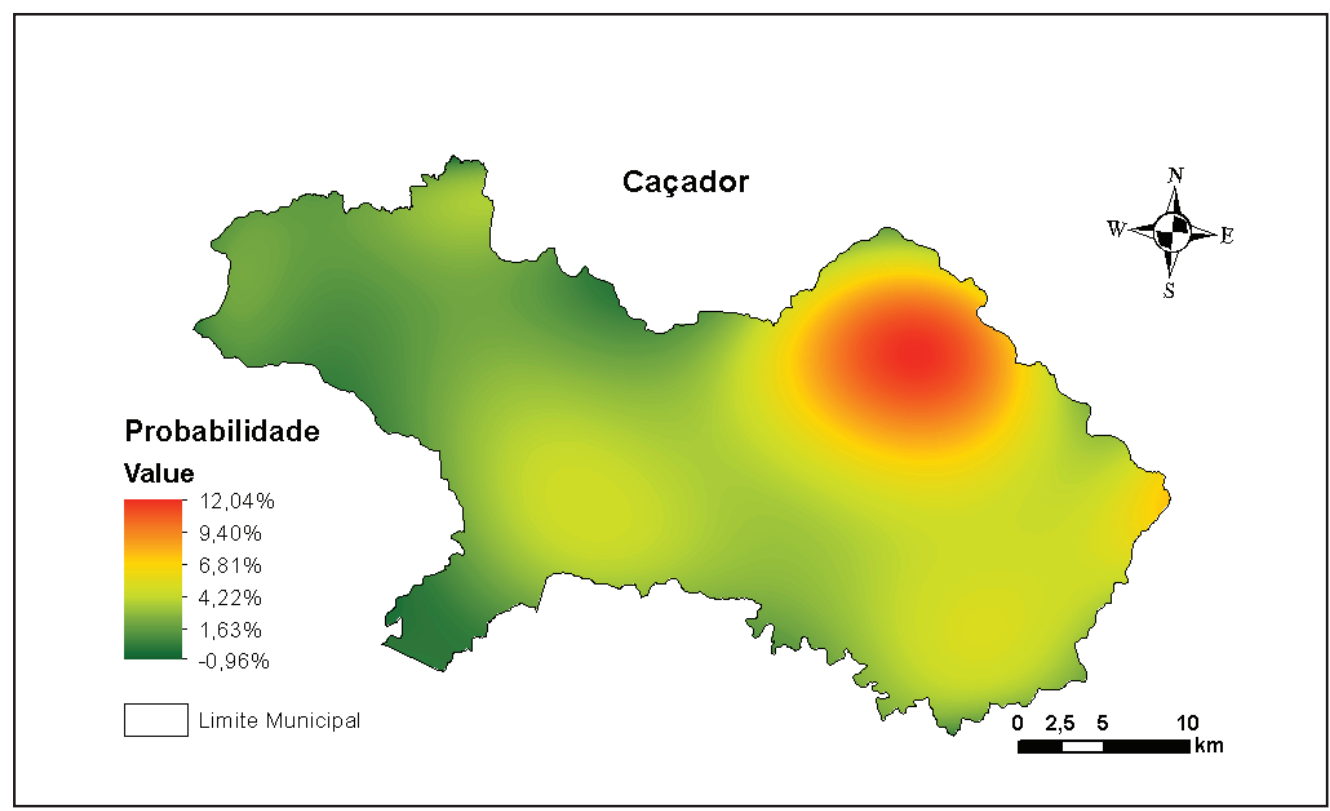

Fonte: Os autores (2018)

\section{Conclusão e resultados}

Neste trabalho foi aplicada uma sequência de procedimentos metodológicos para a classificação, a análise e o monitoramento do uso e cobertura da terra com base em processamento digital de imagens.

Os polígonos gerados na segmentação, do processo de classificação orientada a objetos, representam melhor os limites dos fragmentos florestais, quando comparados a uma classificação tradicional pixel-a-pixel. No entanto, a capacidade de discriminar os segmentos em classes foi ampliada pelo resultado da classificação pixel-a-pixel, incorporada na árvore de processos.

A análise de qualidade, da classificação híbrida, OBIA e pixel-a-pixel, de uso e cobertura da terra para os anos de 2011 e 2014 mostrou que a acurácia global foi superior a 86\%, para os dois anos considerados, atestando o bom resultado obtido com o uso da OBIA. As classes de uso e cobertura da terra mais representativas foram Floresta natural $(2011=47 \%$ e $2014=42 \%)$, Floresta plantada $(2011=28 \%$ e $2014=30 \%)$ e Agricultura e pastagem $(2011=21 \%$ e $2014=23 \%)$ que, somadas, totalizam 96\% para 2011 e $95 \%$ para 2014 .

As maiores alterações, entre os anos de 2011 e 2014, ocorreram nas classes Floresta natural (-4,6\%), Floresta plantada (2,6\%) e Agricultura e pastagem (1,9\%). Já quando se considera somente a classe Floresta natural em relação à expansão ou supressão de área, a classe Agricultura e pastagem foi a que mais teve influência, representando $1,3 \%$ da área suprimida e a classe Floresta plantada representou 0,9\% da área suprimida.

A análise de tendência de mudança de uso e cobertura da terra mostrou que na região nordeste do município concentra-se a maior probabilidade (até 12,04\%) de ocorrer a conversão da classe Floresta natural para classes que contemplem atividades antrópicas. 
Os resultados gerados fornecem subsídios para apoiar o planejamento estratégico de diretrizes que contemplem a gestão do território ao longo do tempo, especialmente o rural. Esse trabalho representa uma estratégia para o monitoramento contínuo de municípios, podendo ser usada na elaboração e revisão de zoneamentos e para a definição de políticas públicas ligadas ao desenvolvimento rural, zoneamentos ecológicos e fiscalização associada a programas para a conservação de determinados usos e cobertura da terra. Também pode ser replicado em outros lugares e permite a geração de cenários de alterações do uso e cobertura da terra, como o impacto de um novo grande empreendimento como uma usina hidrelétrica ou a alteração da delimitação de áreas de proteção ambiental.

\section{References}

ACHARD, F.; OLIVEIRA, Y. M.M. de; MOLLICONE, D. Monitoring forest cover and deforestation. In: Handbook on Remote Sensing for Agricultural Statistics Publication. Global Strategy to improve Agricultural and Rural Statistics (GSARS). p. 185-215, 2017. Disponível em

http://gsars.org/en/handbook-on-remote-sensing-for-agricultural-statistics. Acesso em 24 de abril de 2018.

AGRAWAL, C.; GREEN, G.; GROVE, J.; EVANS, T.; SCHWEIK, C., et al. (2002). A review and assessment of land-use change models: dynamics of space, time, and human choice. Delaware OH: USDA Forest Service. 2002.

AGUIRRE-GUTIÉRREZ, J.; SEIJMONSBERGEN, A.C.; DUIVENVOORDEN, J.F. Optimizing land cover classification accuracy for change detection, a combined pixel-based and object-based approach in a mountainous area in Mexico. Applied Geography 34, 29-37. 2012.

BAATZ, M.; SCH ̈̈PE, A. Object-oriented and multi-scale image analysis in semantic networks. 2nd International Symposium: Operationalization of Remote Sensing, p. 1-7, 1999.

BANCO CENTRAL DO BRASIL (BACEN). RESOLUÇÃO № 4.427, DE 25 DE JUNHO DE 2015. Disponível em: <http://www.bcb.gov.br/pre/normativos/res/2015/pdf/res_4427_v1_O.pdf>. Acesso em: 14 ago. 2017.

BAYFIELD, N. Approaches to Monitoring for Nature Conservation in Scotland. - In: Umweltbundesamt (Federal Environment Agency - Austria) (Ed.): Monitoring for Nature Conservation. Wien (Umweltbundesamt), p. 23-27. ISBN 3-85457-360-X. 1997.

BLASCHKE, T. Object based image analysis for remote sensing. ISPRS Journal of Photogrammetry and Remote Sensing, v. 65, n. 1, p. 2-16, 2010.

BLASCHKE, D. T.; STROBL, P. J. What's wrong with pixels? Some recent developments interfacing remote sensing and GIS. GIS - Zeitschrift für Geoinformationssysteme, v. 14, n. 6, p. 12-17, 2001.

BOCK, M.; XOFIS, P.; MITCHLEY, J.; ROSSNER, G.; WISSEN, M. Object-oriented methods for habitat mapping at multiple scales - Case studies from Northern Germany and Wye Downs, UK. Journal for Nature Conservation 13 (2-3), 75-89. 2005.

BRASIL. Lei no 12.651, de 25 de maio de 2012. Código Florestal. Dispõe sobre a proteção da vegetação nativa; altera as Leis nos 6.938, de 31 de agosto de 1981, 9.393, de 19 de dezembro de 1996, e 11.428, de 22 de dezembro de 2006; revoga as Leis nos 4.771, de 15 de setembro de 1965, e 7.754, de 14 de abril de 1989, e a Medida Provisória no 2.166-67, de 24 de agosto de 2001; e dá outras providências. Diário 
Oficial da União, Brasília, DF, 28 mai. 2012. Disponível em: <http://www.planalto.gov.br/ccivil_03/_ato20112014/2012/lei/L12651compilado.htm>. Acesso em: 09 Dez. 2016.

CLARK LABS. Land Change Modeler (LCM) for ArcGis Software Extension (2.0). 2017. Disponível em: $<$ https://clarklabs.org/land-change-modeler-for-ArcGis/ >. Acesso em: 05 out. 2017.

DI GREGORIO, A. Land cover classification system: classification concepts and user manual: LCCS. Food and Agriculture Organization of the United Nations, 2016.

ESRI. ArcGis Desktop: Release 10.5. Redlands, CA: Environmental Systems Research Institute. 2017.

FARO, J. Facilitación participativa del Plan Estratégico del Bosque Modelo Caçador, Santa Catarina, Brasil. p. 146, 2014.

FEARNSIDE, P. M. Soybean cultivation as a threat to the environment in Brazil. Environmental Conservation, v. 28,23 - 38. 2001.

FIGUEIREDO, G.C.; VIEIRA, C.A.O. Estudo do comportamento dos índices de Exatidão Global, Kappa e Tau, comumente usados para avaliar a classificação de imagens do sensoriamento remoto. In. Anais XIII Simpósio Brasileiro de Sensoriamento Remoto, Florianópolis, Brasil, 21-26 de abril, INPE, p. 5755-5762. 2007.

FINEGOLD, Y.; ORTMANN, A.; LINDQUIST, E.; D'ANNUNZIO, R.; SANDKER, M. Map Accuracy Assessment and Area Estimation Map Accuracy Assessment and Area Estimation: A Practical Guide. Food and Agriculture Organization of the United Nations. National forest monitoring assessment working paper n. 46, p. 69, 2016.

FOLEY, J.A.; DEFRIES, R.; ASNER, G.P.; BARFORD, C.; BONAN, G.; CARPENTER, S.R.; CHAPIN, F.S.; COE, M.T.; DAILY, G.C.; GIBBS, H.K.; HELKOWSKI, J.H.; HOLLO- WAY, T.; HOWARD, E.A.; KUCHARIK, C.J.; MONFREDA, C.; PATZ, J.A.; PRENTICE, I.C.; RAMANKUTTY, N.; SNYDER, P.K. Global consequences of land use. Science 309, 570-574. 2005.

FOODY, G.M. Status of land cover classification accuracy assessment. Remote Sensing of Environment., v. 80, p. 185-201, 2002.

FREIER, K. P.; SCHNEIDER, U. A.; FINCKH, M., et al. Dynamic interactions between vegetation and land use in semi-arid Morocco: using a Markov process for modeling rangelands under climate change. Agriculture, Ecosystems and Environment, 140, 462-472. 2011

FREITAS J.V. et al. Brazil. In: Vidal C., Alberdi I., Hernández Mateo L., Redmond J. (eds) National Forest Inventories. Springer, Cham. p. 197-212, 2016.

GUAN, D., LI, H.; INOHAE, T.; SU, W.; NAGAIE, T.; HOKAO, K., et al. Modeling urban land use change by the integration of cellular automaton and Markov model. Ecological Modelling, 222, 3761-3772. 2011.

HALMY, M. W. A.; GESSLER, P. E.; HICKE, J. A.; SALEM, B. B. et al. Land use/land cover change detection and prediction in the north-western coastal desert of Egypt using Markov-CA. Applied Geography, 63(2015), 101-112. 2015.

HUSSAIN, M.; CHEN, D.; CHENG, A.; WEI, H.; STANLEY, D. Change detection from remotely sensed images: From pixel-based to object-based approaches. ISPRS Journal of Photogrammetry and Remote Sensing, v. 80, p. 91-106. International Society for Photogrammetry and Remote Sensing, Inc. (ISPRS). 2013

INSTITUTO BRASILEIRO DE DESENVOLVIMENTO FLORESTAL (IBDF). Portaria № 560 de 1968. Rio de Janeiro: Instituto Brasileiro de Desenvolvimento Florestal. Disponível em: http://www.icmbio.gov. br/portal/images/stories/imgs-unidades-coservacao/portaria_flona_cacador.pdf. Acesso em: 1 mai. 2016. 
INSTITUTO BRASILEIRO DE GEOGRAFIA E ESTATÍSTICA (IBGE). Manual Técnico da Vegetação Brasileira. 2a edição revista e ampliada. Sistema Fitogeográfico. Inventário das Formações Florestais e Campestres. Técnicas e Manejo de Coleções Botânicas. Procedimentos para Mapeamentos. 2012.

INSTITUTO BRASILEIRO DE GEOGRAFIA E ESTATÍSTICA (IBGE). Base Cartográfica Contínua do Brasil 1:1000000, v4. Base contínua, v. I, n. 4, 2014. Disponível em: ftp://geoftp.ibge.gov.br/cartas_e_mapas / bases_cartograficas_continuas/bcim/versao2014/informacoes_tecnicas/bcim_v4_doc_tecnica_vol_i.pdf . Acesso em: 5 jun. 2017.

INSTITUTO BRASILEIRO DE GEOGRAFIA E ESTATÍSTICA (IBGE). Resolução PR 01/2015, p. 1-8, 2015. Disponível em: ftp://geoftp.ibge.gov.br/metodos_e_outros_documentos_de_referencia/normas/ rpr_01_2015_sirgas2000.pdf. Acesso em: 5 jun. 2017.

INSTITUTO BRASILEIRO DE GEOGRAFIA E ESTATÍSTICA (IBGE). Ferramenta Cidades. 2017b. Disponível em: https://cidades.ibge.gov.br/painel/painel.php?codmun=420300. Acesso em: 5 jun. 2017.

KURASZ, G.; ROSOT, N. C.; OLIVEIRA, Y. M. M. de; ROSOT, M. A. Caracterização Do Entorno Da Reserva Florestal Embrapa / Epagri de Caçador (SC) Usando Imagem Ikonos. Floresta, p. 641-649. ISSN Eletrônico 1982-4688. 2008

LANG, S.; BLASCHKE, T. Análise da paisagem com SIG. Editora Oficina de textos, 424 p. ISBN: 97885-86238-78-9. 2009.

LILLESAND, T. M.; KIEFER, R. W.; CHIPMAN, J. W. Remote sensing and image interpretation. Wiley. 7th Edition. ISBN: 978-1-118-34328-9. 2015.

LU, D.; LI, G.; MORAN, E. Current situation and needs of change detection techniques. International Journal of Image and Data Fusion, v. 5, n. 1, p. 13-38. Taylor \& Francis. 2014.

LU, D.; MAUSEL, P.; BRONDÍZIO, E.; MORAN, E. Change detection techniques. International Journal of Remote Sensing, v. 25, n. 12, p. 2365-2401, 2004.

LUZ, N.; MARAN, J.; GARRASTAZU, M.; ROSOT, M. A.; FRANCISCON, L.; HOLLER, W. A.; GAIAD, N. P.; OLIVEIRA, Y.; FREITAS, J. V. Manual das Unidades Amostrais de Paisagem do Inventário Florestal Nacional Parte I (Procedimentos para a execução do mapeamento de uso e cobertura da terra usando regras de classificação customizadas por UAP ou genéricas, respectivamente). Embrapa Florestas. Colombo. 2018a, no prelo.

LUZ, N.; MARAN, J.; ROSOT, M. A.; GARRASTAZU, M.; FRANCISCON, L.; OLIVEIRA, Y.; FREITAS, J. V. Manual das Unidades Amostrais de Paisagem do Inventário Florestal Nacional Parte II (Procedimentos para a execução do controle de qualidade do mapeamento de uso e cobertura da terra). Embrapa Florestas. Colombo, 2018b, no prelo.

MARKOV, A. A. Extension of the limit theorems of probability theory to a sum of variables connected in a chain. Reimpresso no Apêndice B de: R. Howard. Dynamic Probabilistic Systems, Vol. I: Markov Chains. John Wiley and Sons. 1971.

MINISTÉRIO DO MEIO AMBIENTE (MMA). Geo Catálogo Ministério do Meio Ambiente. 2015. Disponível em: http://geocatalogo.mma.gov.br/. Acesso em: 10 Jun. 2016.

OLOFSSON, P.; FOODY, G. M.; HEROLD, M.; STEHMAN, S. V.; WOODCOCK, C. E.; WULDERE, M. A. Good practices for estimating area and assessing accuracy of land change. Remote Sensing of Environment, v. 148, n. March, p. 42-57. Elsevier Inc. 2014.

PLANET. Rapideye TM Imagery Product Specifications. 2016. Disponível em: https://www.planet. $\mathrm{com} /$ products/satellite-imagery/files/160625-RapidEye Image-Product-Specifications.pdf. Acesso em: 30 abr. 2016. 
PONTIUS JR; R. G. MILLONES, M. Death to kappa: birth of quantity disagreement and allocation disagreement for accuracy assessment. International Journal of Remote Sensing, v. 32, 4407-4429. 2011.

PREFEITURA MUNICIPAL DE CAÇADOR (PMC). Indústria. 2017. Disponível em: http://www. cacador. sc.gov.br/portalhome/cidade/85-industria. Acesso em: 01 fev. 2018.

RADOUX, J.; BOGAERT, P. Good Practices for Object-Based Accuracy Assessment. Remote Sensing, v. 9, n. 7, p. 646, 2017.

RAHMAN, M. T. U.; TABASSUM, F.; RASHEDUZZAMAN, M.; SABA, H.; SARKAR, L.; FERDOUS, J.; UDDIN, S. Z.; ISLAM, A. Z. M. Z. Temporal dynamics of land use land cover change and its prediction using CA-ANN model for southwestern coastal Bangladesh. Environmental Monitoring and Assessment, 189: 565. 2017.

ROSOT, M. A. D.; OLIVEIRA, Y. M. M. DE; RADOMSKI, M. I.; LACERDA, A. E. B. de; GARRASTAZU, M. C.; CARDOSO, D. J.; MATTOS, P. P. de; BRAZ, E. M.; KELLERMAN, B. Bosque Modelo Caçador: concepção e processo de estruturação. 100 p., 2013.

ROSOT M. A. D.; GARRASTAZU, M. C.; HOLLER, W. A.; GAIAD, N.; FRANCISCON, L. Cadernos de geoprocessamento 9: Métodos, técnicas e equipamentos para o processo de reambulação de mapas de uso e cobertura da terra. Embrapa Florestas. Colombo, 2017.

RUHOFF, A.; FANTIN-CRUZ, I; COLLISCHONN, W. Modelos de Simulação Dinâmica do Desmatamento na Amazônia. Caminhos da Geografia, Uberlândia, 1(36): 258-268. ISSN 1678-6343. 2010.

SCHUSTER, C.; FÖRSTER, M.; KLEINSCHMIT, B. Testing the Red Edge channel for improving land-use classifications based on high-resolution multi-spectral satellite data. International Journal of Remote Sensing, v. 33, n. 17, p. 5583-5599. Taylor \& Francis. 2012.

SIMONETTI D.; MARELLI A.; EVA H.D. IMPACT: Portable GIS toolbox image processing and land cover mapping. Luxembourg: Publications Office of the European Union, EUR 27358 EN, ISBN 97892-79-50115-9. 2015.

SMITH, P.; BUSTAMANTE, M.; AHAMMAD, H.; CLARK, H.; DONG, H.; ELSIDDIG, E. A.; HABERL, H.; HARPER, R.; HOUSE, J.; JAFARI, M.; MASERA, O.; MBOW, C.; RAVINDRANATH, N. H.; RICE C. W.; ABAD, C. R.; ROMANOVSKAYA, A.; SPERLING, F.; TUBIELLO, F. 2014: Agriculture, Forestry and Other Land Use (AFOLU). In: Climate Change 2014: Mitigation of Climate Change. Contribution of Working Group III to the Fifth Assessment Report of the Intergovernmental Panel on Climate Change [Edenhofer, O., R. Pichs-Madruga, Y. Sokona, E. Farahani, S. Kadner, K. Seyboth, A. Adler, I. Baum, S. Brunner, P. Eickemeier, B. Kriemann, J. Savolainen, S. Schlömer, C. von Stechow, T. Zwickel and J.C. Minx (eds.)]. Cambridge University Press, Cambridge, United Kingdom and New York, NY, USA. 2014.

SON, N.-T.; CHEN, C.-F. Remote sensing of mangrove forests in Central America. SPIE Newsroom, p. 3, 2013.

STEHMAN, S. V. Sampling designs for accuracy assessment of land cover, International Journal of Remote Sensing, 30:20, 5243-5272, 2009.

STEHMAN, S.V.; CZAPLEWSKI, R.L. Design and analysis for thematic map accuracy assessment: fundamental principles. Remote Sensing of Environment, v. 64, 331-344. 1998.

STEHMAN, S.V.; WICKHAM, J.D. Pixels, blocks of pixels, and polygons: Choosing a spatial unit for thematic accuracy assessment. Remote Sensing of Environment, v. 115, 3044-3055. 2011.

STRAHLER, A.; BOSCHETTI, L.; FOODY, G. M.; FIEDL, M. A.; HANSEN, M. C.; HEROLD, M.; MORISETTE, J. T.; STEHMAN, S. V.; WOODCOCK, C. E. Global land cover validation: Recommendations for evaluation and accuracy assessment of global land cover maps. EUR22156EN. (51 pp.). Luxembourg: Office for Official Publications of the European Communities. 2006. 
SULSOFT. ENVI 5. 2017. Disponível em: < http://www.sulsoft.com.br/pdf/envi.pdf >. Acesso em: 20 jun. 2017.

TRIMBLE. eCognition. 2017. Disponível em: < http://www.ecognition.com/ >. Acesso em: 30 abr. 2017.

TURNER II, B. L.; LAMBIN, E. F.; REENBERG, A. The emergence of land change science for global. v. 104, n. 52, p. 20666-20672. Proceedings of the National Academy of Sciences of the United States of America. 2007.

VÁCLAVÍK, T.; ROGAN, J. Identifying Trends in Land Use/Land Cover Changes in the Context of Post-Socialist Transformation in Central Europe: A Case Study of the Greater Olomouc Region, Czech Republic. GIScience \& Remote Sensing, v. 46, n. 1, p. 54-76. Taylor \& Francis. 2009.

VELDKAMP, A.; LAMBIN, E. F. Predicting land use change. Agriculture. Ecosystems \& Environment, 85, 1-6. 2001.

WASHINGTON-ALLEN, R. A.; RAMSEY, R. D.; WEST, N. E. Spatiotemporal mapping of the dry season vegetation response of sagebrush steppe. Community Ecology. vol.5, nํ1, p.69-79, 2004. 